Portland State University

PDXScholar

$5-24-2019$

\title{
Social Correlates of Paternal Postpartum Depression: a Statistical Analysis
}

Sonia Bosch

Portland State University

Follow this and additional works at: https://pdxscholar.library.pdx.edu/honorstheses Let us know how access to this document benefits you.

\section{Recommended Citation}

Bosch, Sonia, "Social Correlates of Paternal Postpartum Depression: a Statistical Analysis" (2019). University Honors Theses. Paper 679.

https://doi.org/10.15760/honors.695

This Thesis is brought to you for free and open access. It has been accepted for inclusion in University Honors Theses by an authorized administrator of PDXScholar. Please contact us if we can make this document more accessible: pdxscholar@pdx.edu. 
Social Correlates of Paternal Postpartum Depression: A Statistical Analysis

Written by

Sonia Bosch

An undergraduate honors thesis submitted in partial fulfillment of the requirements for the degree of

Bachelor of Science

in

University Honors

and

Sociology

Thesis Adviser

Emily Shafer

Portland State University 


\section{Table of Contents}

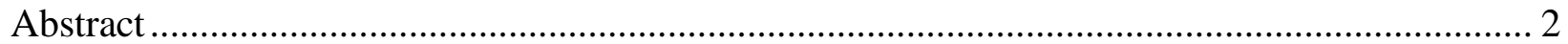

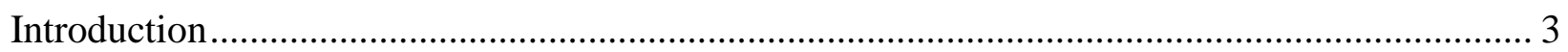

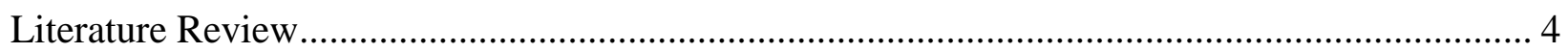

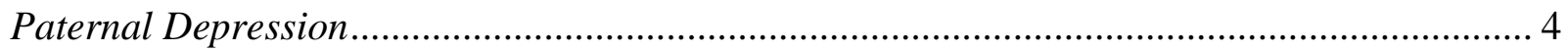

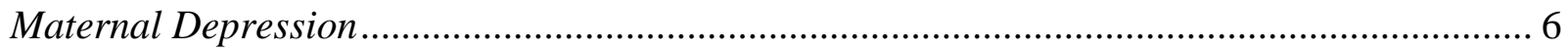

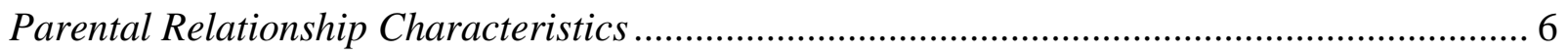

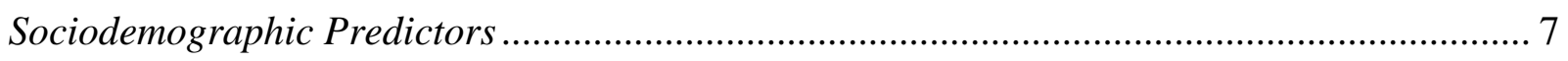

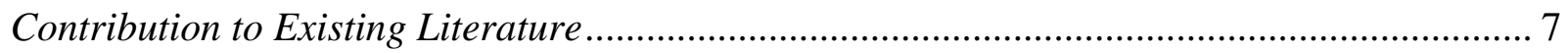

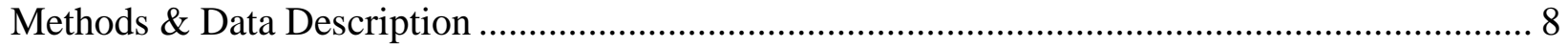

Sample

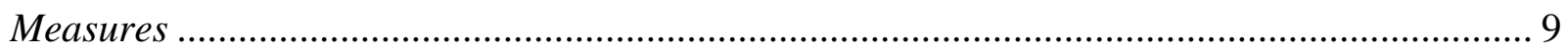

Method

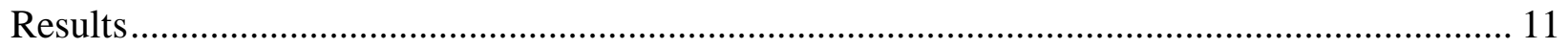

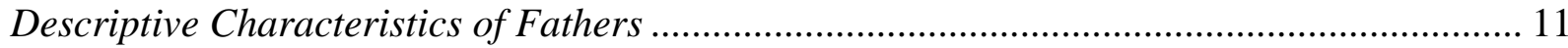

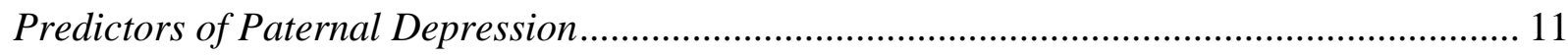

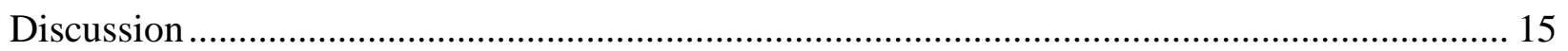

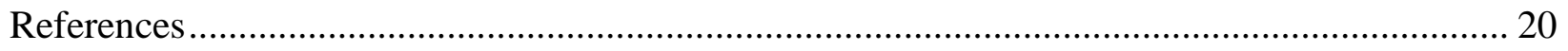




\begin{abstract}
By looking at paternal depression one year after childbirth using the year one data of the Fragile Families and Child Wellbeing Survey (FFCWS), I aim to understand whether maternal postpartum depression is significantly related to the development of paternal postpartum depression. Additionally, I aim to understand whether sociodemographic variables and relationship variables alter the statistical relationship between maternal and paternal postpartum depression. Initially, when examined alone, maternal depression is significantly related to paternal depression $(\mathrm{p}<0.05)$. However, once relationship variables were included as control variables in the model, the relationship between maternal depression and paternal depression became statistically insignificant. I recoded data from the FFCWS dataset and conducted statistical analysis of these variables using binomial logistic regressions in SPSS. This study contributes to the discourse surrounding paternal postpartum depression and what variables are most influential in its development. Implications of this study include finding effective interventions on an interpersonal and clinical level, as well as a larger sociocultural level to mitigate the consequences of postpartum depression on families.
\end{abstract}

Key Words: paternal postpartum depression, maternal postpartum depression, relationship status, relationship quality, mental health, logistic regression, family 


\section{Introduction}

Postpartum depression (PPD) is classified by clinicians and researchers as a major depressive episode that sets in within one year after childbirth (Ohara, 2009). It is a serious mood disorder that makes caring for oneself or others more challenging. If left untreated, the depression can be prolonged and interfere with the health of the parent(s) and/or the development of the newborn. Postpartum depression occurs in fathers as well as mothers (Ballard \& Davies, 1996; Escribà-Agüir et al., 2008; Paulson \& Bazemore, 2010). Recent psychiatric research suggests that paternal depression during a child's life up to age 16 "may be associated with child's behavioral and developmental problems, poor school performance, and increased risk of psychiatric disorders" (Gentile \& Fusco, 2017). Consequently, if both parents are experiencing postpartum depression there may be a sharply increased risk of hindering their child's well-being and development.

Awareness of postpartum depression is crucial to ensuring that those experiencing symptoms can seek helpful treatment. Research indicates that men tend to not disclose emotional distress with physicians and that typical depressive symptomatology does not entirely encompass the experiences of men (Wide et al., 2011). Paternal postpartum depression occurs at lower rates than maternal postpartum depression (Kessler, 2003). However, unawareness and invisibility of paternal PPD combined with a masculine standard of not seeking care for depressive symptoms

(Wide et al., 2011; Mangocevic \& Addis, 2008) have the potential to be detrimental to high-risk individuals that may be going untreated. Research on postpartum depression in fathers is relatively new compared to research on maternal postpartum depression, but the discourse surrounding paternal postpartum depression is developing and I aim to contribute to the growth of the discourse and gain new insights on paternal postpartum depression. 
My research question is as follows: Does a relationship exist between maternal and paternal postpartum depression at one year postpartum, and do relationship status, income, age, and educational attainment attenuate the relationship between maternal depression and paternal depression? With this study, I aim to build off Chien-Chung Huang and Linda A. Warner's 2005 study on depression in fathers with newborns. Huang and Warner find that characteristics of the relationship between fathers and mothers do significantly correlate to major depressive episodes at one year postpartum (2005). The study mostly elaborates on the quality of the relationship itself, substance abuse, and demographic characteristics such as socioeconomic status and ethnicity. They find that increases in supportiveness decrease the likelihood of depressive episodes in fathers (2005). Huang and Warner account for depressive symptoms at birth for the father as a predictor for depressive symptoms at the one-year mark. To extend on the understanding of paternal depression, I will control for relationship quality and other social variables such as father's education level, age, and household income. Instead of investigating the connections between relationship supportiveness and paternal depression, I will be controlling for it, and other variables, while primarily investigating the relationship between maternal depression and paternal depression.

\section{Literature Review}

\section{Paternal Depression}

Postpartum depression is a mood disorder that occurs in the about 8-10\% of new fathers worldwide, and 14\% of new fathers in the U.S. (Cameron et al. 2016; Paulson \& Bazemore 2010). The research on postpartum depression has been primarily focused on mothers, so research on paternal postpartum depression is relatively new (Cetisli et al. 2016). The highest rates of paternal postpartum depression occur around 3-6 months after birth (Cameron et al. 
2016; Paulson \& Bazemore, 2010). Around 11\% of participants in a 2017 study on the progression of depressive symptomatology in Italian first-time fathers were classified as having emergent depression where they exhibited depressive symptoms close to the clinical cutoff during pregnancy to 6 months after childbirth and then at 1 year after birth, the fathers met all clinical criteria for depression (Molgora et al., 2017). Overall, the research shows that paternal postpartum depression is a significant phenomenon warranting further investigation.

Paternal postpartum depression is highly influenced by social variables and therefore fluctuates more than maternal postpartum depression which has more internal psychobiological influence and less prone to fluctuations (Molgora et. al, 2017). Some biological factors for fathers are highlighted such as changes in estrogen, vasopressin, prolactin during pregnancy with a concurrent decrease in testosterone (Harrison \& White 2017). Any change in hormones increases the chance of significantly altering an individual's mood. While hormone changes increase vulnerability to depression, hormonal changes that men tend to experience during the prenatal period are associated with being primed to bond during and after childbirth (Harrison \& White 2017), so the biological influences are open for interrogation.

Fathers experiencing postpartum depression, face barriers such as stigma surrounding mental health disparities which serves as a barrier to seeking clinical attention (Edward et al. 2015). Even though the experience of paternal postpartum depression is not consistent in the long-term like maternal postpartum depression, it still has documented long term consequences on childhood development. Children of fathers with paternal postpartum depression are at higher risk for developing mental health disorders in the future such as anxiety, depression, hyperactivity, emotional disorders, and behavioral disorders (Cetisli et al. 2016; Escriba-Aguir \& Artazcoz 2011; Gentile \& Fusco 2017; Molgora et al., 2016). 


\section{Maternal Depression}

In general, mothers are more likely to develop postpartum depression than fathers (Escriba-Aguir \& Artazcoz 2011). In several studies, researchers found that maternal depression is one of the strongest predictors of paternal depression in the postnatal period (Cameron et al.2016; Goodman 2004; Paulson \& Bazemore 2010; Schumacher 2008). Maternal postpartum depression shares some parallel predictors with paternal postpartum depression such as prenatal depression, low social support, history of depression, and marital status (Beck 2001; Edward et al. 2014; Freitas et al. 2016; Huang \& Warner 2005; Top et al. 2016). Women who go through negative life experiences are more likely to develop depression in the postpartum period (Escriba-Aguir \& Artazcoz 2011). In financial terms, untreated maternal depression is estimated to cost families roughly $\$ 25,000$ annually which includes the costs of impaired functioning in the workplace and the costs related to child health problems (Freitas 2016). Untreated maternal postpartum depression can also lead to infanticide and/or suicide in severe cases (Zhang \& Jin 2014).

\section{Parental Relationship Characteristics}

In concurrence with findings on social support and postpartum depression, increased paternal involvement in the household reduces the negative effect of having a child on relationship quality, especially for mothers (McClain \& Brown 2017). When fathers spend more time in childcare, it conveys strong social support and a good relationship quality to mothers. Social support and positive relationship quality are found to be a protective factor in regards to postpartum depression (Dush 2013; Escriba-Aguir et al. 2008; Freitas et al. 2016; Huang \& Warner, 2005; Zhang \& Jin 2014), while poor relationship quality and dissolution of the relationship is noted as a significant risk factor (Dush 2013; Escriba-Aguir \& Artazcoz 2011). In 
terms of relationship status, married fathers are significantly less likely to experience postpartum depression than fathers that are not romantically involved with mothers (Huang \& Warner 2005). However, married fathers that report low social support also report more mental health problems including depressive symptoms (Huang \& Warner 2005).

\section{Sociodemographic Predictors}

As is true with many mental health disorders, lower socioeconomic status is associated with higher rates of depression (Huang \& Warner, 2005 p.100). In general, individuals with higher educational attainment tend to have higher socioeconomic status, and the ability to postpone the manifestation of depressive symptoms is contingent on a higher education level (Miech \& Shanahan 2000). Men are most likely to begin experiencing depression their twenties and thirties (Huang \& Warner, 2005 p.100). In addition, young age at marriage and lower educational attainment are significant predictors of divorce, which is connected to increased risk of depressive symptoms (Dush 2013).

\section{Contribution to Existing Literature}

What the literature doesn't tell us is how these statistical relationships look in more diverse samples, as well as the cross-cultural prevalence of paternal postpartum depression for families that are especially vulnerable. By utilizing the FFCWS I will be contributing to this gap in the literature by running my analysis with a sample containing a greater proportion of identities that are typically underrepresented in research on, and treatment of, mental health. Previous studies on paternal postpartum depression have focused on white educated men (Goodman 2004), so using data from the FFCWS will incorporate data from more low-income respondents and include a greater representation of nonwhite respondents. This study will serve to replicate previous work that has found a significant relationship between maternal postpartum 
depression and paternal postpartum depression. My results will either reaffirm or contradict the existing body of research which argues that maternal depression predicts paternal depression in the postnatal period while encompassing a more sociodemographically diverse sample than the current body of research represents.

\section{Methods \& Data Description}

\section{Sample}

The following statistical analysis employs the use of the year 1 wave of the Fragile Families and Child Wellbeing Survey (FFCWS). The FFCWS is conducted by Columbia and Princeton University and actively follows approximately 5,000 children that were born in 20 major U.S. cities (populations over 200,000) between 1998 and 2000. FFCWS provides largescale longitudinal survey data available for public use with extensive information on new parents and their mental health, relationship characteristics, educational attainment, and other social demographics in the United States.

Participants were recruited in hospitals. Mothers were recruited and interviewed within 48 hours of giving birth, and fathers were interviewed as close to the birth as possible either in the hospital, clinic, or other location. Around $3 / 4$ of the couples interviewed were unmarried at baseline. This study utilizes the year one (wave 2) data where follow-up interviews were conducted about one year after the birth and baseline data collection. Year one data was collected in the years 1999-2001. One of the core aims of the survey is to better understand the circumstances and potential for specifically fathers and unmarried couples. The focus on fathers, families, and socially precarious conditions make the FFCWS ideal for my analysis. For this study, I combined the mother dataset with the father dataset from the year one wave. My sample 
is limited to mothers and fathers that were screened for depression using the CIDI-SF assessment and that provided valid responses to all my included control variables $(\mathrm{N}=2,779)$.

\section{Measures}

Depression- The depression scale utilized by the FFCWS wave 2 interviews is the Composite International Diagnostic Interview (CIDI) Short-Form (CIDI-SF). The CIDI was created for use by trained interviewers that are not mental health practitioners or clinicians (Kessler et al. 1998). The CIDI-SF incorporates DSM-IV (APA, 1994) criteria for significant distress and impairment to functioning (1998). The CIDI-SF classification for major depressive episode (MDE) is 93.9\% consistent with the long-form CIDI (1998). In order to meet CIDI-SF Kessler \& Mroczek's (1994) depression criteria for this study, respondents must report experiencing dysphoric mood (psychological suffering) or anhedonia (disinterest in activities/significantly decreased enjoyment) every day for at least half the day for two weeks.

Limitations of the CIDI-SF uses criteria from the DSM-IV which is outdated by today's clinical standards with the release of the DSM-V and the Edinburgh Postnatal Depression Scale (EPDS). However, the classification requirements of the CIDI-SF are in accordance with the diagnostic criteria available at the time that wave 2 of the FFCWS was being collected, and the purpose of the short-form interview is to gather data for measurement, rather than for clinical diagnosis. Both paternal and maternal depression were re-coded as dummy variables where meeting the depression criteria is the reference category coded as 1 , and not meeting the depression criteria is coded as 0 .

Relationship Variables- Relationship status and relationship quality are control variables included to better understand the role of romantic relationships and social support in regard to paternal postpartum depression. At year 1, fathers were asked how their relationship with the 
mother of their child is. The relationship quality variable is categorical and coded as (0) poor, (1) fair, (2) good, (3) very good and (4) excellent with all other responses coded as missing. Relationship status is also categorical and indicates whether couples are (1) married, (2) romantic cohabitating, (3) romantic not cohabitating (4) separated/divorced/widowed, and (5) not in a romantic relationship. All responses outside of these categories are coded as missing.

Sociodemographic characteristics- The sociodemographic variables analyzed in this study are age, educational attainment, and household income. Age is a scale variable with absent responses and refusal to respond are coded as missing. Educational attainment is coded as an ordinal variable with the following categories: (1) less than high school, (2) high school or equivalent (GED), (3) some college or technical degree, and (4) bachelor's or graduate degree. All other responses are coded as missing. Household income is also coded as a categorical variable separated into six brackets: (1) $\$ 0-\$ 15,000$, (2) $\$ 15,001-\$ 30,000$, (3) $\$ 30,001-\$ 50,000$ (4) $\$ 50,001-\$ 80,000,(5) \$ 80,001-\$ 100,000,(6) \$ 100,000+$.

\section{Method}

Using SPSS, I will run frequencies on my variables for maternal postpartum depression and paternal postpartum depression. Then I will run binomial logistic regressions to build multiple models for analysis. First, with just my independent and dependent variable alone (maternal and paternal PPD), and then adding my control variables to observe the changes in correlation values and p-values. 


\section{Results}

Descriptive Characteristics of Fathers

As shown in Table 1, 10.4 percent of fathers in the sample have depression within 1 year after birth, and 15.5 percent of mothers in the sample have depression. These percentages reflect the average distribution of depression that is outlined in the literature. Household income for the sample is skewed to the left with 74.2 percent of the sample having an annual household income of $\$ 50,000$ or less, and 54.1 percent of the sample having an annual household income of $\$ 30,000$ or less, and almost 30 percent of the sample were living near the threshold of the federal poverty guideline in 1996 for a family of three. 62.2 percent of fathers in the sample have an education level of high school degree or less. These demographic results convey that our sample is representative of mostly working-class people.

In terms of the relationship between mothers and fathers, a majority of the sample of fathers report being in a romantic relationship with the mother of their child, with 30.2 percent of couples reporting being married. Almost 85 percent of fathers reported good or above average relationship quality with the mother of their child. Around 10 percent of fathers reported fair relationship quality, and approximately 5.5 percent reported poor relationship quality with the mother of their child.

\section{Predictors of Paternal Depression}

After employing list-wise deletion for cases with missing data on any of the variables in the analysis, the final sample size included in all three of my regression models was narrowed to 2,779. Table 2 shows the results of the three logistical regression models. Model 1 analyzed maternal postpartum depression alone and shows that maternal depression is positively correlated with paternal depression one year after childbirth. This model alone showed 
statistically significant results. However, once I introduced marital status as a control variable in Model 2, the maternal depression variable became insignificant. In Model 3, I added the relationship quality variable, and found that relationship quality is also statistically significant, even when controlling for marital status, maternal depression, and sociodemographic variables. Relationship quality also further weakened the correlation value of maternal depression. Based on these findings, I infer that maternal postpartum depression is not related to paternal postpartum depression.

In another model (results not shown) I ran an additional binomial logistic regression between maternal depression (IV) and paternal depression (DV) with the sample restricted to only married respondents and romantic cohabitating respondents. I ran this additional regression because based on my findings in the literature, I thought that fathers exposed to mothers with PPD in daily life would possibly be more likely to develop symptoms of PPD. However, this model did not yield significant results, further indicating that maternal depression is not related to paternal depression, and father's exposure to maternal postpartum depression via marriage or cohabitation is also not related to an increased risk of developing paternal postpartum depression. The results of these models indicate that the initial significant correlation between maternal postpartum depression and paternal postpartum depression in Model 1 is spurious.

The models in Table 2 do seem to show that the variables for relationship quality and relationship status between mothers and fathers are both significantly related to paternal postpartum depression. Without controlling for relationship quality, Model 2 shows that fathers having a romantic relationship with the mother of their child is significantly related to a decreased likelihood of the development of paternal postpartum depression, and the strength of that correlation decreases if the couple does not live together. In Model 3, when all variables are 


\section{Table 1}

Descriptive Statistics

\begin{tabular}{|c|c|c|c|}
\hline Variable & & $\mathrm{n}$ & $\%$ \\
\hline \multirow[t]{2}{*}{ Paternal Depression } & Not Depressed & 2,486 & 89.5 \\
\hline & Depressed & 293 & 10.5 \\
\hline \multirow[t]{2}{*}{ Maternal Depression } & Not Depressed & 2,359 & 84.9 \\
\hline & Depressed & 420 & 15.1 \\
\hline \multirow[t]{6}{*}{ Household Income } & $\$ 0-\$ 15,000$ & 718 & 25.8 \\
\hline & $\$ 15,001-\$ 30,000$ & 713 & 25.7 \\
\hline & $\$ 30,001-\$ 50,000$ & 594 & 21.4 \\
\hline & $\$ 50,001-\$ 80,000$ & 478 & 17.2 \\
\hline & $\$ 80,001-\$ 100,000$ & 119 & 4.3 \\
\hline & $\$ 100,001+$ & 157 & 5.6 \\
\hline \multirow[t]{5}{*}{ Relationship Status } & Married & 1005 & 36.2 \\
\hline & Romantic Cohabitating & 887 & 31.9 \\
\hline & Romantic Not Cohabitating & 275 & 9.9 \\
\hline & Separated/Widowed/Divorced & 41 & 1.5 \\
\hline & No Romantic Relationship & 571 & 20.5 \\
\hline \multirow[t]{4}{*}{ Father's Education Level } & Less than High School & 818 & 29.4 \\
\hline & High School or Equivalent & 901 & 32.4 \\
\hline & Some College or Technical Degree & 701 & 25.2 \\
\hline & College or Graduate Degree & 359 & 12.9 \\
\hline \multirow[t]{5}{*}{ Relationship Quality } & Poor & 147 & 5.3 \\
\hline & Fair & 267 & 9.6 \\
\hline & Good & 561 & 20.2 \\
\hline & Very Good & 882 & 31.7 \\
\hline & Excellent & 922 & 33.2 \\
\hline
\end{tabular}


Table 2

Predictors of Paternal Postpartum Depression at 1 Year

\begin{tabular}{|c|c|c|c|c|c|c|}
\hline \multirow[b]{2}{*}{ Variable } & \multicolumn{2}{|c|}{ Model 1} & \multicolumn{2}{|c|}{ Model 2} & \multicolumn{2}{|c|}{ Model 3} \\
\hline & Coefficient & S.E. & Coefficient & S.E. & Coefficient & S.E. \\
\hline Maternal Depression & 0.379 & $0.147^{*}$ & 0.229 & 0.153 & 0.168 & 0.166 \\
\hline \multicolumn{7}{|l|}{ Household Income } \\
\hline$\$ 0-\$ 15,000$ & - & - & 0.401 & 0.348 & 0.488 & 0.381 \\
\hline$\$ 15,001-\$ 30,000$ & - & - & 0.234 & 0.347 & 0.261 & 0.380 \\
\hline$\$ 30,001-\$ 50,000$ & - & - & 0.221 & 0.347 & 0.208 & 0.379 \\
\hline$\$ 50,001-\$ 80,000$ & - & - & 0.21 & 0.349 & 0.028 & 0.385 \\
\hline$\$ 80,001-\$ 100,000$ & - & - & 0.228 & 0.442 & 0.374 & 0.468 \\
\hline$\$ 100,001+$ & - & - & & & & \\
\hline \multicolumn{7}{|l|}{ Relationship Status } \\
\hline Married & - & - & -1.212 & $0.171^{* *}$ & -0.370 & $0.204 *$ \\
\hline Romantic Cohabitating & - & - & -1.174 & $0.157^{* *}$ & -0.527 & $0.182^{* *}$ \\
\hline Romantic Not Cohabitating & - & - & -0.482 & $0.194 *$ & -0.106 & 0.225 \\
\hline Separated/Widowed/Divorced & - & - & 0.194 & 0.333 & 0.485 & 0.385 \\
\hline No Romantic Relationship & - & - & & & & \\
\hline Father Age 1 Year After Childbirth & - & - & -0.010 & 0.009 & -0.003 & 0.010 \\
\hline \multicolumn{7}{|l|}{ Father Education Level } \\
\hline Less than High School & - & - & 0.028 & 0.259 & -0.110 & 0.283 \\
\hline High School or Equivalent & - & - & -0.307 & 0.256 & -0.414 & 0.279 \\
\hline Some College or Technical Degree & - & - & -0.075 & 0.246 & -0.126 & 0.267 \\
\hline College or Graduate Degree & - & - & & & & \\
\hline \multicolumn{7}{|l|}{ Relationship Quality } \\
\hline Poor & - & - & - & - & 1.934 & $0.265^{* *}$ \\
\hline Fair & - & - & - & - & 1.591 & $0.23^{* *}$ \\
\hline Good & - & - & - & - & 1.014 & $0.208^{* *}$ \\
\hline Very Good & - & - & - & - & 0.483 & $0.204 *$ \\
\hline Excellent & - & - & - & - & & \\
\hline Constant & -2.231 & $0.064 * *$ & -1.347 & $0.456^{*}$ & -2.714 & $0.523^{* *}$ \\
\hline
\end{tabular}

Note: $\mathrm{N}=2,779$

$* \mathrm{p}<0.05$

$* * \mathrm{p}<0.01$ 
being controlled for, marriage and romantic cohabitation are negatively correlated with paternal depression $(\mathrm{p}<0.05)$, so fathers that are married or romantically cohabitating with the mother of their child are less likely to experience a depressive episode within one year after childbirth. All categories of relationship quality were positively related to experiencing paternal postpartum depression $(\mathrm{p}<0.05)$ with the strength of the correlation decreasing as relationship quality increased.

\section{Discussion}

Contrary to most of the findings of existing literature, the results of these models suggest that mothers experiencing postpartum depression is not related to fathers developing postpartum depression. My findings instead suggest that characteristics of the relationship between new mothers and fathers are related to the likelihood that fathers will develop a major depressive episode within the first year of childbirth. These findings refute the findings of much of the existing literature on paternal postpartum depression which show that maternal PPD and paternal PPD are significantly related. The majority of the studies that are widely cited in reference to the significant relationship between maternal and paternal depression are meta-analyses and literature searches which summarize the findings of the discourse community rather than replicating specific studies to support or refute the findings (Cameron et al.2016; Goodman 2004; Paulson \& Bazemore 2010; Schumacher 2008). Though, the review of a body of findings indicates the general trends and findings of previous research.

There is a growing body of research on paternal postpartum depression that utilizes statistical analysis which has come to the similar conclusion that maternal postpartum depression is not a statistically significant predictor of paternal postpartum depression (Paulson et al. 2016; Roubinov et al. 2014; Top et al. 2016) are not A more recent study that investigates the 
interaction of paternal and maternal postpartum depression through binary logistic regression, as I have employed, found that maternal depression does not predict paternal depression, but that for parents that both express depressive symptomology, mother's exposure to paternal postpartum depression did tend to worsen mother's depressive symptoms (Paulson et al. 2016). So, while they found no predictive relationship in that direction, they did still find a significant interaction between maternal and paternal postpartum depression in terms of paternal postpartum depression worsening the severity of symptoms of maternal postpartum depression. They attribute these findings to their sample fathers returning to work relatively quickly, and therefore not being exposed to their partner's depressive symptoms frequently (Paulson et al. 2016), which may hold true to families in my analytic sample where the majority are in lower income brackets and therefore may be unable to take extended leave from work.

Additionally, in a 2014 study on postpartum depression in Mexican American fathers, researchers also found no correlation between maternal postpartum depression and paternal postpartum depression (Roubinov et al. 2014). Roubinov et al.'s 2014 study had a sample of Mexican American fathers that were mostly lower income compared to Paulson et al.'s 2016 study which included mostly white middle-class individuals. My results support the findings of these studies which contributes to the body of literature that suggests that maternal and paternal depression are unrelated, though this disparity of findings indicates a gap that warrants further investigation into maternal postpartum depression being influential in the development of paternal postpartum depression.

Relationship status and relationship quality are both significantly related to paternal postpartum depression, indicating that social support and family dynamics are more influential in determining the risk of paternal postpartum depression than mother's postpartum depression. My 
findings support the literature regarding the significance of relationship status and relationship quality between mothers and fathers (Escriba-Aguir et al. 2008; Freitas et al. 2016; Huang \& Warner 2005). Literature indicates that dissolving relationships and poor relationship quality increase the risk of depression in fathers (Dush 2013; Escriba-Aguir \& Artazcoz 2011), and my findings indicate that being in a stable romantic relationship, as well as good relationship quality reduce the risk of fathers having postpartum depression. Based on these findings, I further contend that gendered expectations pertaining to the allocation of housework and paid work in the family are connected to marital satisfaction. Increased work and family conflicts tend to lower marital satisfaction, which is an established predictor of depression and postpartum depression for both mothers and fathers (Escriba-Aguir \& Artazcoz 2011; Paulson \& Bazemore 2010; Top et al. 2016). Implications of findings on the significance of relationship quality and relationship status between new parents can be applied to the clinical and family level, as well as the macro or sociocultural level. I argue that when couples have children, gender roles become more stratified, which is referred to by McClain and Brown as "role traditionalization" in their 2017 study. Role traditionalization is more prominent for new mothers as they generally reduce their engagement with the labor force and increase their time spent in housework, including childcare, while men tend to spend less time in housework and more time in the labor force (McClain \& Brown 2017).

The shift in gender expectations can put a strain on partnerships because mothers take on much more household work which is unpaid work. In turn, when fathers are more involved in the private sphere and, in turn, more involved in co-parenting, mothers perceive more fairness in the relationship (McClain \& Brown 2017). Fathers tend to return to work earlier than mothers and may have more social contact that mitigates the risk of developing depressive symptoms via 
exposure to their partner's depression (Paulson et al. 2016), however their relationship quality may suffer because of that distance. Based on my findings that relationship quality and relationship status between mothers and fathers are significantly related to the development of paternal depression, I argue that the movement toward more equal allocation of housework is a meaningful advance toward lessening strain on status and quality of relationships between mothers and fathers, especially during the heightened stresses of early parenthood and newborn childcare.

Father's involvement in household work may not only alleviate strain on their romantic partnership and reduce their risk of experiencing a major depressive disorder, but also may contribute to a larger cultural shift in gendered expectations over time. Fathers establishing a standard of increasing their engagement with unpaid housework would close the gap that is referred to as 'the Stalled Revolution’ by sociologist Arlie Hochschild (2012). On average, women have made rapid social change in terms of their engagement with higher education and the public workforce, but that change has not been reciprocated by men making significant changes to their engagement in work that has been traditionally relegated to women i.e. cleaning, laundry, childcare, eldercare, cooking, and other domestic chores. Families that resist role traditionalization are likely to see positive outcomes in their relationship and their mental health. Family is typically the primary mode of socialization, so fathers will also be modeling more egalitarian behavior when resisting role traditionalization after childbirth and values that will likely be passed along to their children and therefore contributing to progress toward establishing more gender egalitarian structures beginning in the family.

The results of this study should be carefully interpreted with contextual limitations in mind. The results of this study do not imply causal relationship between any variables. 
Limitations of this study include the outdated scale of measuring depression. The CIDI-SF encompassed diagnostic criteria at the time of data collection, but future research should examine samples that use the EPDS to measure postpartum depression rather than the CIDI-SF as the EPDS is the most widely used screening criteria today. However, current research suggests that the diagnostic criteria for depression may not fully encompass men's experience of depression because depressive symptomatology does not line up with masculine socialization (Mangocevic \& Addis, 2008).

There are two potential reasons that men are diagnosed with depression at much lower rates than women. First, men are much less likely than women to speak freely about their emotions and, further, disclose their struggles with mood disorders like depression due to the socialized constraints of hegemonic masculinity which subordinates the feminine and results in men transforming their more vulnerable emotions in an attempt to manage them (Connell \& Messerschmidt 2005; Pfeffer et al. 2016). Second, the current diagnostic criteria for depression and major depressive episodes may not be aligned with the ways that men experience depression and depressive symptoms (Wide et al., 2011; Mangocevic \& Addis, 2008), which is a possible additional barrier to men obtaining clinical resources or support. These experiences of masculine depression can include aggression, heightened sex drive, feelings of inadequacy, and substance abuse (Mangocevic \& Addis, 2008).

Future researchers may also employ newer data that more accurately captures new fathers today and their experiences with mental health in our current social context. The way that we perceive and treat mental health disorders is constantly under review, and it is important that we recognize the cultural context that families are living in to thoroughly understand the social standards that individuals may have been subject to. These social standards as they pertain to 
gendered expectations seem to be contributing to increased risks of fathers experiencing postpartum depression, and there is the potential that men experiencing depression could be underrepresented in survey samples due to the traditionally feminized symptomology of depression as well as the cultural feminization, and therefore devaluation, of mood disorders. Future researchers should also continue to investigate more samples that encompass the experiences of marginalized groups, and low-income families to build a more inclusive body of research that may point to cultural or demographic differences in mental health.

\section{References}

Ballard, C., \& Davies, R. (1996). Postnatal depression in fathers. International Review of Psychiatry, 8(1), 65-71. doi:10.3109/09540269609037818

Beck, C. T. (2001). Predictors of Postpartum Depression. Nursing Research, 50(5), 275-285. doi:10.1097/00006199-200109000-00004

Cameron, E. E., Sedov, I. D., \& Tomfohr-Madsen, L. M. (2016). Prevalence of paternal depression in pregnancy and the postpartum: An updated meta-analysis. Journal of Affective Disorders, 206, 189-203. doi:10.1016/j.jad.2016.07.044

Connell, R. W., \& Messerschmidt, J. W. (2005). “Hegemonic Masculinity: Rethinking the Concept.” Gender \& Society,19(6), 829-859. doi:10.1177/0891243205278639

Dush, C. M. (2013). Marital and Cohabitation Dissolution and Parental Depressive Symptoms in Fragile Families. Journal of Marriage and Family, 75(1), 91-109. doi:10.1111/j.1741-3737.2012.01020.x

Escriba-Aguir, V., \& Artazcoz, L. (2011). Gender differences in postpartum depression: A longitudinal cohort study. Journal of Epidemiology and Community Health, 65, 320-326. doi:10.1136/jech.2008.085894 
Escribà-Agüir, V., Gonzalez-Galarzo, M., Barona-Vilar, C., \& Artazcoz, L. (2008). Factors related to depression during pregnancy: Are there gender differences? Journal of Epidemiology and Community Health (1979-), 62(5), 410-414. doi:10.1136/jech.2007.063016

Edward, K., Castle, D., Mills, C., Davis, L., \& Casey, J. (2014). An Integrative Review of Paternal Depression. American Journal of Mens Health, 9(1), 26-34. doi: $10.1177 / 1557988314526614$

Freitas, C. J., Williams-Reade, J., Distelberg, B., Fox, C. A., \& Lister, Z. (2016). Paternal depression during pregnancy and postpartum: An international Delphi study. Journal of Affective Disorders, 202, 128-136. doi:10.1016/j.jad.2016.05.056

Gentile, S., \& Fusco, M. L. (2017). Untreated perinatal paternal depression: Effects on offspring. Psychiatry Research, 252, 325-332. doi:10.1016/j.psychres.2017.02.064

Genuchi, M. C., \& Mitsunaga, L. K. (2015). Sex Differences in Masculine Depression. The Journal of Mens Studies, 23(3), 243-251. doi:10.1177/1060826514561986

Goodman, J. H. (2004). Paternal postpartum depression, its relationship to maternal postpartum depression, and implications for family health. Journal of Advanced Nursing, 45(1), 26-35. doi:10.1046/j.1365-2648.2003.02857.x

Harrison, Y., \& White, M. (2017). How postpartum depression can affect new fathers. Urology Times, 45(8), 28-30.

Hochschild, A. R., \& Machung, A. (2012). The Second Shift: Working Parents and the Revolution at Home. New York: Penguin Books.

Huang, C., \& Warner, L. (2005). Relationship Characteristics and Depression among Fathers with Newborns. Social Service Review, 79(1), 95-118. doi:10.1086/426719 
Kessler, R. C. (2003). Epidemiology of Women and Depression. Journal of Affective Disorders, 74(1), 5-13. doi:10.1016/s0165-0327(02)00426-3

Kessler, R. C., Andrews, G., Mroczek, D., Ustun, B., \& Wittchen, H. (1998). The World Health Organization Composite International Diagnostic Interview short-form (CIDI-SF). International Journal of Methods in Psychiatric Research, 7(4), 171-185. doi:10.1002/mpr.47

Magovcevic, M., \& Addis, M. E. (2008). The Masculine Depression Scale: Development and psychometric evaluation. Psychology of Men \& Masculinity, 9(3), 117-132. doi:10.1037/1524-9220.9.3.117

Mcclain, L., \& Brown, S. L. (2016). The Roles of Fathers' Involvement and Coparenting in Relationship Quality among Cohabiting and Married Parents. Sex Roles, 76(5-6), 334-345. doi:10.1007/s11199-016-0612-3

Miech, R. A., \& Shanahan, M. J. (2000). Socioeconomic Status and Depression over the Life Course. Journal of Health and Social Behavior, 41(2), 162-176. doi:10.2307/2676303

Molgora, S., Fenaroli, V., Malgaroli, M., \& Saita, E. (2016). Trajectories of Postpartum Depression in Italian First-Time Fathers. American Journal of Mens Health, 11(4), 880-887. doi:10.1177/1557988316677692

Newmann, J. (1987). Gender Differences in Vulnerability to Depression. Social Service Review, $61(3), 447-468$.

Ohara, M. W. (2009). Postpartum depression: What we know. Journal of Clinical Psychology, 65(12), 1258-1269. doi:10.1002/jclp.20644

Ohara, M. W., \& Swain, A. M. (1996). Rates and risk of postpartum depression-a meta-analysis. International Review of Psychiatry, 8(1), 37-54. 
doi:10.3109/09540269609037816

Paulson, J. F., \& Bazemore, S. D. (2010). Prenatal and Postpartum Depression in Fathers and Its Association With Maternal Depression. Jama, 303(19), 1961. doi:10.1001/jama.2010.605

Paulson, J. F., Bazemore, S. D., Goodman, J. H., \& Leiferman, J. A. (2016). The course and interrelationship of maternal and paternal perinatal depression. Archives of women's mental health, 19(4), 655-663. doi:10.1007/s00737-016-0598-4

Pfeffer, C. A., Rogalin, C. L., \& Gee, C. A. (2016). Masculinities Through a Cross-Disciplinary Lens: Lessons from Sociology and Psychology. Sociology Compass, 10(8), 652-672. doi:10.1111/soc4.12396

Roubinov, D. S., Luecken, L. J., Crnic, K. A., \& Gonzales, N. A. (2014). Postnatal depression in Mexican American fathers: Demographic, cultural, and familial predictors. Journal of Affective Disorders, 152-154, 360-368. doi:10.1016/j.jad.2013.09.038

Schumacher, M., Zubaran, C., \& White, G. (2008). Bringing birth-related paternal depression to the fore. Women and Birth, 21(2), 65-70. doi:10.1016/j.wombi.2008.03.008

Top, E. D., Cetisli, N. E., Guclu, S., \& Zengin, E. B. (2016). Paternal Depression Rates in Prenatal and Postpartum Periods and Affecting Factors. Archives of Psychiatric Nursing, 30(6), 747-752. doi:10.1016/j.apnu.2016.07.005

Wide, J., Mok, H., McKenna, M., \& Ogrodniczuk, J. S. (2011). Effect of gender socialization on the presentation of depression among men: A pilot study. Canadian family physician Medecin de famille canadien, 57(2), e74-e78.

Zhang, Y., \& Jin, S. (2014). The impact of social support on postpartum depression: The mediator role of self-efficacy. Journal of Health Psychology, 21(5), 720-726. doi:10.1177/1359105314536454 